УДК 324(73)

DOI 10.52575/2687-0967-2021-48-1-249-258

\title{
Развитие цифровой политической агитации: от Говарда Дина к Дональду Трампу
}

\author{
А.А. Завьялов \\ Нижегородский госуниверситет им. Н.И. Лобачевского, \\ Россия, 603005, г. Нижний Новгород, ул. Ульянова, 2 \\ Cark2015@yandex.ru
}

\begin{abstract}
Аннотация. Целью данной работы было выделить изменения способов агитации, в частности использование социальных медиа в предвыборных кампаниях. В качестве основного метода при написании статьи использовался метод кейсов. В частности, были выбраны предвыборные кампании нескольких президентов Соединенных Штатов Америки. Основным результатом является то, что, исследуя развитие политических групп в социальных сетях, мы можем наблюдать за происходящим в режиме реального времени. В будущем это могло бы помочь выявить группы избирателей, которые голосуют на основе убеждений, сформированных социальными медиа, и лучше понять как поведение электората, так и проблемы, которые мотивируют избирателей. Изучение социальных медиа позволяет наблюдать за этими процессами онлайн, в то время как опросы и анализ в традиционных СМИ не дают такой возможности.
\end{abstract}

Ключевые слова: микротаргетинг, персонализация, интерактивность, избирательная кампания, социальные страницы, политические блогеры, подписчиков, политическая агитации, социальные медиа.

Для цитирования: Завьялов А.А. 2021. Развитие цифровой политической агитации: от Говарда Дина к Дональду Трампу. Via in tempore. История. Политология, 48 (1): 249-258. DOI: $10.52575 / 2687-0967-2021-48-1-249-258$.

\section{Development of digital political agitation: from Howard Dean to Donald Trump}

\author{
Artur A. Zavyalov \\ Lobachevsky State University of Nizhny Novgorod, \\ 2 Ulyanova St., Nizhnij Novgorod, 603005, Russia \\ E-mail: cark2015@yandex.ru
}

\begin{abstract}
The aim of this work was to highlight the changes in the methods of agitation, particular the use of social media in election campaigns. As the main method for writing the article, was used the case method. In particular, the election campaigns of several presidents of the United States of America. By examining the development of political groups in social networks, we can observe what is happening in real time. In the future, this could help identify groups of voters who vote based on the beliefs formed by social media, and better understand both the behavior of the electorate and the problems that motivate voters. The study of social media allows you to watch these processes online, while surveys and analysis in traditional media do not provide such an opportunity.
\end{abstract}

Keywords: microtargeting, personalization, interactivity, election campaign, social pages, political bloggers, subscribers, political agitation, social media.

For citation: Zavyalov A.A. 2021. Development of digital political agitation: from Howard Dean to Donald Trump. Via in tempore. History and political science, 48 (1): 249-258 (in Russian). DOI: $10.52575 / 2687-0967-2021-48-1-249-258$. 
Социальные сети с самого начала своего существования привлекли внимание не только маркетологов как инструмент онлайн-продаж, но и политтехнологов как новый канал борьбы в предвыборной гонке. Ключевую роль здесь играет возможность сегментации своей целевой аудитории и точечная работа с ней. Что в результате дает возможность тщательно обработать запросы каждого сегмента аудитории в ходе предвыборной кампании.

Выборы 2004-го года, и в частности основная кампания Говарда Дина, стали поворотным пунктом в использовании цифровых технологий в предвыборных кампаниях. Г. Дин был губернатором штата Вермонт и претендовал на то, чтобы стать кандидатом от демократической партии на пост президента. В итоге он стал фаворитом на выдвижение.

Кампания Г. Дина использовала блоги как способ привлечения сторонников для постоянного участия в предвыборной кампании [Trippi, Kerbel, Bloom, 2005]. Блог «Дин для Америки» ежедневно обновлялся информацией, касающейся предвыборных мероприятий, агитационными темами и ссылками на новости о кампании.

Кампания также проводила конкурсы, где сторонники могли бы стать «гостем блогера». Также блог использовали, чтобы попросить совета у избирателей относительно выступлений и агитационных мероприятий. По словам руководителя предвыборной кампании Джо Триппи, «Мы не просто контролировали эти блоги, мы слушали, мы использовали обратную связь. Были времена, когда мы изменяли речь Дина, прислушиваясь к предпочтениям подписчиков блога, или же меняли стратегию нашей кампании» [Trippi, 2005, p. 146].

Кампания Дина изменила структуру пожертвований на избирательные кампании. Раньше, до возникновения интернета, кампании использовали сложные схемы по сбору средств (например, обеды и концерты). В 2004 г. сайты кандидатов обеспечили пространство для сбора пожертвований без больших расходов на кампании по сбору средств. Изменился механизм пожертвований на избирательные кампании. Крупные суммы денег собираются из небольших пожертвований благодаря куда более широкой аудитории сторонников.

Эта модель позволила Г. Дину стать претендентом на статус кандидата от Демократической партии. Во время своей основной кампании Г. Дин собрал более 40 млн долларов благодаря небольшим пожертвованиям со средней суммой взноса \$143 [Singel, 2004].

Удачным примером персонализации и интерактивности был так называемый «Обед с Г. Дином» (идея, предложенная блогером Дина). С аккаунта кампания кандидата отправляла его фотографию, где он ест бутерброд с индейкой, и призывала сторонников пожертвовать $\$ 50$ в обмен на возможность «пообедать» с Г. Дином онлайн. В результате внедрения новых организационных и коммуникационных структур его кампания совершила подлинную онлайн-мобилизацию. И хотя попытка Г. Дина стать кандидатом от демократов была неудачной, избирательные новшества стали весьма популярными. Промежуточные выборы 2006 года были первыми выборами, в которых социальные медиа активно использовались в ходе избирательной кампании. Хотя и в зачаточной стадии, деятельность кампаний посредством Facebook и YouTube удостоилась значительного внимания избирателей и ведущих СМИ.

Facebook предоставил всем основным кандидатам от демократической партии в Конгресс возможность создать профиль на странице Facebook и наполнить его контентом. Подобное приглашение было воспринято с энтузиазмом, но только 32 \% кандидатов в Сенат и 13 \% тех, кто работал в Белом Доме, создали свой профиль [Christine, 2009].

В 2006 году кампаниями в качестве рекламного инструмента в основном использовался YouTube, в дополнение к телевидению и радио. Ha YouTube, наряду с бла- 
гоприятными видео о кандидатах от демократической партии, размещались также их нелестные и компрометирующие материалы об оппонентах. Например, поражение сенатора от штата Коннектикут Джозефа Либермана было отчасти связано с неблагоприятным содержанием интервью, загруженного на YouTube [Gueorguieva, 2008, p. 288-300].

Тем не менее в то время темпы внедрения социальных медиа по-прежнему были незначительны. Президентские выборы 2008 года отличались координацией цифровых технологий и использованием социальных медиа. Термин «социальные медиа-выборы» 2008 года появился благодаря тому, что кампании начали активнее использовать такие pecyрсы, как Facebook, YouTube и Twitter.

Барак Обама, в частности, был назван «королем социальных медиа» за вовлечение избирателей в свою кампанию посредством различных социальных медиа [Vargas, 2007].

К 2008 году каждый избиратель мог стать блогером, появилась возможность заводить свои собственные блоги о кандидатах и их кампаниях, что способствовало их взаимодействию с другими избирателями, а также кандидатами.

Сайты кампаний становились пристанищем потенциальных сторонников, теперь они предоставляли пространство для самовыражения электората и усиливали связь с кандидатом.

Кампании очень активно использовали микротаргетинг с помощью рассылок и баз данных. Кампания Обамы составила внушительный список адресов электронной почты - более 13 миллионов адресов [Vargas, 2008]. Была разработана сложная база данных о потенциальных избирателях. Кроме того, кампания собирала информацию через свой веб-сайт и социальные страницы, она объединила эту информацию с демографическими данными, особенностями района и образа жизни.

В сущности, кампания Обамы создала некий набор приоритетов для различных избирателей и разработала уникальные коммуникационные стратегии для каждого из них. Во время выборов кампания разослала более 7000 различных сообщений, направленных конкретным избирателям. С учетом общего списка рассылки команда Обамы отправила 1 млрд писем [Vargas, 2008]. Например, если вы имели детей и были бы крайне обеспокоены их будущим, кампания отправляла вам по электронной почте свою программу о политике в области образования, а не одну лишь информацию по реформе налоговой системы [Madden, 2008].

Выборы 2008-го года также отличались усилиями по сбору средств. Во время первичных выборов кандидат от Республиканской партии Рон Пол стал своего рода рекордсменом, собрав в Интернете \$ 6 млн долларов за сутки. А в течение своей избирательной кампании Обама собрал рекордные полмиллиарда долларов с помощью пожертвований через Интернет со средним взносом в размере 80 долларов [Vargas, 2008]. Не является случайным совпадением и тот факт, что кандидаты, которые смогли собрать большое количество средств, использовали интерактивный подход.

К концу выборов 2008 года страница Обамы на Facebook имела более 2 млн сторонников (в то время как его республиканский соперник Джон Маккейн имел чуть более 600000 человек) [Fraser, Dutta, p. 2008]. Страница Обамы на Facebook, например, включала информацию о его любимых музыкантах (Майлз Дэвис, Стиви Уандер и Боб Дилан), описывала его увлечение баскетболом и характеризовала как примерного семьянина [Fraser, Dutta, 2008].

Рекламируя себя подобным образом, он стал более близким и понятным для избирателей, стал восприниматься не только как политик, но и как обычный человек. Для сравнения, на странице Джона Маккейна в Facebook рыбалка была указана как его любимое занятие, а «Письма с Иводзимы» - любимый фильм, то есть, по сути, информа- 
ция, могущая заинтересовать лишь людей старшего возраста, и абсолютно индифферентная для молодых пользователей Facebook.

Президентские выборы 2008 года также способствовали интерактивности на YouTube. Обе кампании, Маккейна и Обамы, поддерживали официальные каналы на YouTube, загружали видео, начиная с телевизионных рекламных роликов и заканчивая личными обращениями [Cortese, Proffitt, 2009]. Видео, как правило, является примером персонализации с акцентом на личные качества кандидата.

Кевин Воллстен обнаружил, что политические блогеры и рассылка писем и сообщений сыграли решающую роль в привлечении избирателей [Wallsten, 2010]. В конечном счете кампания Обамы была более успешной, чем у противников, во многом благодаря именно YouTube как инструменту предвыборной кампании. Канал Обамы получил более 97 миллионов просмотров видео и 18 миллионов посещений, в то время как канал Маккейна привлек только 25 млн просмотров видео и 2 млн посещений [Fraser, Dutta, 2008].

Twitter также вышел на политическую арену в 2008 году. Как социальные медиа, Twitter принес кампании Обамы свыше 125000 подписчиков по сравнению с 5300 у Маккейна [Rasiej, Sifry, 2008]. Но кандидаты в 2008 году только начинали использовать Twitter, как и избиратели (только 4 процента американских интернетпользователей были зарегистрированы в Twitter в 2008 году). В течение следующего года количество пользователей Twitter выросло на 200 процентов, что свидетельствовало о быстрой адаптации электората к новым социальным медиа [Williams, Gulati, 2007].

Новые методы кампании имеют большой потенциал, давая возможность избирателю быть на «передовой» избирательных баталий и самому участвовать в процессе избрания.

Статистические данные подтверждают тот факт, что социальные сети предлагают избирателям, и особенно молодежи, новое пространство, где они могут делиться политическими взглядами, участвовать в политике [Youth Voting, 2010]. Хотя и следует констатировать, что лишь небольшая часть американской молодежи включилась в этот процесс в ходе компании 2008 года. Но их число растет, так как новые методы продолжают глубоко интегрироваться в избирательные кампании, обеспечивая постоянное участие избирателей.

Учитывая, что главная задача любой избирательной кампании состоит в привлечении голосов, главный вопрос заключается в понимании, каковы возможности социальных медиа в формировании политических предпочтений граждан. Доказательства влияния социальных медиа на этот процесс весьма неоднозначны. Хоть выборные кампании 2008 и 2010 годов активно использовали «социальные медиа» для мобилизации молодых людей, явка среди молодежи оставалась сравнительно низкой. С другой стороны, априори использование социальных медиа предполагает положительное косвенное влияние.

Нам представляется очевидным, что использование социальных медиа в избирательных кампаниях в значительной степени влияет на явку. Например, число поклонников того или иного политика на Facebook позволяет судить, насколько успешным на выборах будет тот или иной кандидат. Например, для выборов 2008 года Facebook paзработал кнопку «Я проголосовал!», чтобы пользователи могли сообщить своим друзьям в Facebook, что они проголосовали. Более 5,4 миллиона пользователей зафиксировали в социальной сети, что они участвовали в голосовании в тот день [Vargas, 2008].

Во время президентских праймериз 2008 года поддержка на Facebook для кандидата являлась более важным показателем по сравнению с традиционными приемами по сбору средств, освещению в СМИ и агитационными мероприятиями. Те кандидаты, которые имели свой профиль, получили больше голосов, чем кандидаты, его не имев- 
шие [Williams, Gulati, 2007]. Однако эта поддержка не обязательно приводит к победе, и традиционные ресурсы все еще играют важную роль в политической агитации.

Во время президентских выборов 2008 года молодые люди, которые были наиболее политически активными в социальных медиа, отдавали предпочтение Обаме, нежели Маккейну, но это может являться отличительной чертой лишь этих выборов [Bode, Vraga, Borah, Shah, 2014]. Кампания Обамы имела куда больше оснований претендовать на голоса молодых людей, чем кампания Маккейна, и поэтому делала особый упор на новые социальные медиа.

Выборы предполагают не только увеличение объема политической информации, но и мотивирование избирателей, чтобы узнать о политике больше и принять в ней участие. В результате новые методы кампании воздействуют на избирателей через получение политической информации и ее обсуждение. Таким образом, использование цифровых средств массовой информации позволяет гражданам облегчить доступ к тому информационному контенту, который их интересует. Например, те, кто предпочитает политической информации развлекательную, не будут получать первую. Допустим, если вы не будете подписаны на некоего политика, то он не будет «всплывать» в вашем Twitter, a сообщения ваших друзей о политике на Facebook будут быстро отфильтровываться.

Эмпирические доказательства относительно новых методов кампании указывают на увеличение потенциала для селективного потребления информации, так как на веб-ресурсах информация обеспечивает более высокие уровни интерактивности, где пользователи могут выбирать исключительно те разделы, которые их интересуют.

Интернет позволяет знакомиться исключительно с тем политическим контентом, который человек выбирает. Также люди, которые глубоко сопереживают во время предвыборной кампании по поводу конкретной проблемы, как правило, сосредотачиваются на получении дополнительной информации о таковой и даже опираются на пути решения этой проблемы в качестве основного критерия в процессе принятия решения при голосовании.

По сути, социальные медиа являются пространством, где Интернетпользователи сталкиваются с приемлемой и неприемлемой информацией. Исследования показали, что молодые люди участвуют в политическом диалоге в социальных медиа, размещают различные комментарии о политических вопросах, которые стимулируют дополнительные обсуждения.

Исследования подтверждает, что те, кто подвергается политической агитации посредством Facebook, YouTube или Twitter, лучше запоминают эту информацию. Политическое содержание сайтов социальных медиа может отражать общественное мнение, по крайней мере, относительно определенных тем. Исследования показыв ают, что социальные медиа способствуют тому, что пользователи начинают знакомиться и с той информацией, которая ранее рассматривалась ими как категорически неприемлемая [Bode, Vraga, Borah, Shah, 2014].

Избирательные кампании предоставляют возможность участия в политической жизни, что очень важно для развития и совершенствования настоящей демократии. Социальные медиа обладают способностью перемещения онлайн-участия в традиционное автономное участие в политической жизни, например, посредством пожертвования денег или ношения символики кампании.

Ранние исследования кампаний в социальных медиа показали их общее негативное воздействие на пользователей. Серьезной проблемой было то, что социальные медиа сделали участие в политике слишком простым. «В один щелчок "мыши“», пользователи могли «подписать» онлайн-петиции или поддержать голосом [Morozov, 2009]. Однако большинство исследований показывают, что виртуальные социальные медиа все же дополняют традиционные модели поведения, а не заменяют их, особенно среди 
молодежи. Участие в политической деятельности посредством социальных медиа, как правило, положительно влияет на классические средства политического участия [Christensen, 2011].

Например, в течение выборов 2008 года участие подростков в политической деятельности на сайтах социальных сетей способствовало их участию в реальной политической деятельности. А политически ориентированное использование социальных медиа привело к автономному участию в ходе избирательного цикла [Bode, Vraga, Borah, Shah, 2014]. Даже такая простая деятельность, как просмотр страниц политических кандидатов, способствовала повышению политической активности [Towner, Dulio, 2011].

Таким образом, использование цифровых средств массовой информации, особенно социальных медиа, таких как Facebook, YouTube и Twitter, привнесли новые методы политической агитации. Микротаргетинг, персонализация, интерактивность и постоянная вовлеченность были использованы в различных избирательных кампаниях и стали новыми формами их проведения.

Нет сомнений в том, что социальные медиа усиливают вовлеченность в процесс голосования. Но совершенно очевидно, что использование социальных медиа во время кампании будет наиболее эффективным в сочетании с традиционными ресурсами, такими как предвыборные мероприятия и участие традиционных СМИ.

В начале своего пути в Белый Дом Дональд Трамп не пользовался особой популярностью в американских печатных СМИ. В то время как порядка 200 газет и журналов публиковали материалы с поддержкой Хилари Клинтон, лишь 20 поддержали Трампа.

Победа Трампа была жестоким ударом для его политических противников. Но это было и унижением тысяч журналистов, которые месяцами пытались сформировать в сознании миллионов американцев его отрицательный образ.

Джефф Джарвис, профессор городского университета Нью-Йорка, активный сторонник Хиллари Клинтон, заявил об этом просто: «Сам факт выдвижения кандидатуры Дональда Трампа свидетельствует о провале журналистики» [Trump supporters on Twitter..., 2016]. Он, как и многие другие представители либеральных СМИ, считает, что успех Трампа является признаком того, что СМИ не смогли донести правду с достаточной силой.

Безусловно, телевидение как основной доминирующий новостной источник стало отправной точкой роста популярности Трампа. Но далее раскруткой его популярности занялись социальные медиа, в частности его излюбленный Twitter.

В разгар предвыборной кампании аналитики социальных сетей из организации Impact Social изучали публикации в Twitter и других социальных сетях. Анализируя публикации, выяснили, что Трамп намного опередил Клинтон по количеству положительных комментариев.

Это связано с тем, что Трамп, как правило, провоцирует «троллинг» аудитории, побуждая ее обсуждать его высказывания, придавая им тем самым общественный резонанс. Яркие заголовки в Twitter, обыгрывающие проблематику повседневных процессов, происходящих в американском обществе, обеспечивали максимальный спрос на его канал в Twitter, что в геометрической прогрессии множило число подписчиков Трампа.

В свою очередь, подписчики сами инициировали всевозможные обсуждения, вовлекая новых симпатизантов совершенно бесплатно. Таковая, казалось бы, самодеятельная вовлеченность, в какой-то степени причастность к созданию новостного контента давала людям ощущение открытости кандидата обществу.

Помимо этого, эпатажный образ Трампа был более интересным и интригующим и вызывал все больше эмоций. В какой-то момент предвыборной гонки в новостной 
ленте можно было встретить посты с Трампом практически у всех пользователей социальных сетей. Подобными нестандартными приемами он постепенно, шаг за шагом завоевывал свою победу в битве за «голоса» в Интернете.

Трамп, постоянный пользователь Twitter, где он делится с десятками миллионов своих подписчиков своими мыслями и намерениями «сделать Америку снова великой!» [Trump credits social media..., 2019]. По приблизительным подсчетам аккаунты Трампа в социальных сетях объединяют около 125 миллионов подписчиков в Twitter, Instagram и Facebook.

Использование Трампом социальных сетей позволило ему избежать «фальшивых» традиционных СМИ, которые, по его словам, относятся к нему «очень несправедливо» [Trump credits social media..., 2019]. По словам президента, Twitter и другие социальные медиа позволяют увидеть реальное отношение аудитории к той или иной политической проблеме, что позволяет администрации получать моментальную обратную связь относительно текущих политических процессов. Главное отличие социальных медиа от традиционных - это то, что потребители новостного контента в социальных медиа могут сразу включиться в обсуждение в комментариях, что позволяет отслеживать реакцию аудитории в реальном времени и по мере развития дискуссии влиять на ее развитие.

Избрание Дональда Трампа президентом удивило почти всех, и не в последнюю очередь политических аналитиков и ученых. Долго шумевший слух об участии «русских хакеров» в предвыборной кампании Трампа привел к тому, что были проведены исследования активности в социальных сетях в этот период. Выбрав около 250000 учетных записей, обнаружили, что во время выборов образовалась группа сторонников Трампа и Республиканской партии в социальной сети. Но, к большому удивлению, среди них было задействовано очень мало ботов или так называемых «русских аккаунтов». Это говорит о том, что даже если бы русские спецслужбы и хотели бы повлиять на выборы, то эффект от их действий был бы ничтожно мал, нежели это представляли СМИ. (Как известно, специальный прокурор США Роберт Мюллер в своем докладе заявил об отсутствии «русского следа» в избирательной кампании Дональда Трампа.)

Исследуя развитие политических групп в социальных сетях, мы можем наблюдать за происходящим в режиме реального времени. В грядущих избирательных кампаниях это поможет выявлять группы избирателей, которые голосуют на основе убеждений сформированных современными медиа, и лучше понять как поведение электората, так и проблемы, которые мотивируют избирателей. Изучение социальных медиа позволяет наблюдать за этими процессами онлайн, в то время как опросы и анализ в традиционных СМИ не дают такой возможности.

Таким образом, использование цифровых средств массовой информации, особенно социальных медиа, таких как Facebook, YouTube, и Twitter, привнесло новые методы политической агитации. Микротаргетинг, персонализация, интерактивность и постоянная вовлеченность были использованы в различных избирательных кампаниях и стали новыми формами их проведения.

Нет сомнений в том, что социальные медиа усиливают вовлеченность в процесс голосования. Но совершенно очевидно, что использование социальных медиа во время кампании будет наиболее эффективным в сочетании с традиционными ресурсами, такими как традиционные предвыборные мероприятия с обязательным участием традиционных СМИ. 


\section{Список литературы}

1. Bode L., Vraga E.K. 2014. Porismita Borah and Dhavan V. Shah, A New Space for Political Behavior: Political Social Networking and Its Democratic Consequences. Journal of Computer-Mediated Communication, Volume 19, Issue 3, April

2. Christensen H.S. 2011. Political Activities on the Internet: Slacktivism or Political Participation by Other Means? First Monday, Vol. 16.

3. Cortese J., Proffitt J.M. 2009. Political Messages in the First Presidential YouTube Election: A Content Analysis of the 2008 Presidential Candidates' YouTube Sites (paper presented at the annual conference of the Association of Education in Journalism and Mass Communication), Boston, Massachusetts, August 5-8.

4. Fraser M., Dutta S. 2008. "Barack Obama and the Facebook Election," US News and World Report, November 19. URL: http://www.usnews.com/opinion/articles/2008/11/19/barackobama-and-the-facebook-election (дата обращения: 04.10.2020).

5. Gueorguieva V. 2008. Voters, MySpace, and YouTube: The Impact of Alternative Communication Channels on the 2006 Election Cycle and Beyond. Social Science Computer Review, 26: $288-300$.

6. Madden M. 2008. Barack Obama's Super Marketing Machine, Salon, July 16. URL: http://www.salon.com/2008/07/16/obama_data/ (дата обращения: 16.09.2020).

7. Morozov E. 2009. The Brave New World of Slacktivism, Foreign Policy, 19 May. URL: https://foreignpolicy.com/2009/05/19/the-brave-new-world-of-slacktivism/. (дата обращения: 26.06.2015)

8. Rasiej A., Sifry M.L. 2008. The Web: 2008's Winning Ticket, Politico, November 12. URL: http://www.politico.com/story/2008/11/the-web-2008s-winning-ticket-015520 (дата обращения: 11.08.2020).

9. Singel R. 2004. Net Politics Down but Not Out, Wired, February 2, (дата доступа: 17.09.2015). (URL) http://archive.wired.com/politics/law/news/2004/02/62123.

10. Towner T.L., Dulio D. 2011. The Web 2.0 Election: Does the Online Medium Matter? The Journal of Political Marketing, 10: 165-188.

11. Trippi J., Kerbel M.R., Bloom J.D. 2005. Blog for America and Civic Involvement. Harvard International Journal of Press/Politics, 10: 3-27.

12. Trump credits social media for his election. URL: https://www.politico.com/story/2019/10/20/trump-social-media-election-244009.

13. Trump supporters on Twitter during 2016 US election show little evidence of Russian infiltration - new research. URL: https://theconversation.com/trump-supporters-on-twitter-during2016-us-election-show-little-evidence-of-russian-infiltration-new-research-115188.

14. Vargas J.A. 2007. Barack Obama, Social Networking King. The Washington Post, October 6. http://voices.washingtonpost.com/44/2007/10/06/barack_obama_social_networking.html_ (дата обращения: 13.09.2020).

15. Vargas J.A. 2008. Obama Raised Half a Billion Online. The Washington Post, November 20. URL: http://voices.washingtonpost.com/44/2008/11/20/obama_raised_half_a_billion_on.html. (дата обращения: 15.09.2020).

16. Voting Y. 2010. CIRCLE (Center for Information and Research on Civic Learning and Engagement). URL: http://www.civicyouth.org/quick-facts/youth-voting/ (дата обращения: 11.08.2015).

17. Wallsten K. 2010. Yes We Can': How Online Viewership, Blog Discussion, Campaign Statements, and Mainstream Media Coverage Produced a Viral Video Phenomenon. Journal of Information Technology \& Politics, 7: 163-181.

18. Williams Ch.B., Gulati G.J. 2007. Social Networks in Political Campaigns: Facebook and the 2006 Midterm Election, (paper presented at the annual meeting of the American Political Science Association), Chicago, Illinois, 30 August - 2 September.

19. Williams Ch.B., Gula. ti G.J. 2009. Social Networks in Political Campaigns: Facebook and Congressional Elections 2006, 2008. APSA Toronto Meeting Paper 7. 


\section{References}

1. Bode L., Vraga E.K. 2014. Porismita Borah and Dhavan V. Shah, A New Space for Political Behavior: Political Social Networking and Its Democratic Consequences. Journal of Computer-Mediated Communication, Volume 19, Issue 3, April

2. Christensen H.S. 2011. Political Activities on the Internet: Slacktivism or Political Participation by Other Means? First Monday, Vol. 16.

3. Cortese J., Proffitt J.M. 2009. Political Messages in the First Presidential YouTube Election: A Content Analysis of the 2008 Presidential Candidates' YouTube Sites (paper presented at the annual conference of the Association of Education in Journalism and Mass Communication), Boston, Massachusetts, August 5-8.

4. Fraser M., Dutta S. 2008. "Barack Obama and the Facebook Election," US News and World Report, November 19. URL: http://www.usnews.com/opinion/articles/2008/11/19/barackobama-and-the-facebook-election (дата обращения: 04.10.2020).

5. Gueorguieva V. 2008. Voters, MySpace, and YouTube: The Impact of Alternative Communication Channels on the 2006 Election Cycle and Beyond. Social Science Computer Review, 26: $288-300$.

6. Madden M. 2008. Barack Obama's Super Marketing Machine, Salon, July 16. URL: http://www.salon.com/2008/07/16/obama_data/ (дата обращения: 16.09.2020).

7. Morozov E. 2009. The Brave New World of Slacktivism, Foreign Policy, 19 May. URL: https://foreignpolicy.com/2009/05/19/the-brave-new-world-of-slacktivism/. (дата обращения: 26.06.2015)

8. Rasiej A., Sifry M.L. 2008. The Web: 2008's Winning Ticket, Politico, November 12. URL: $\quad$ http://www.politico.com/story/2008/11/the-web-2008s-winning-ticket-015520 (дата обращения: 11.08.2020).

9. Singel R. 2004. Net Politics Down but Not Out, Wired, February 2, (дата доступа: 17.09.2015). (URL) http://archive.wired.com/politics/law/news/2004/02/62123.

10. Towner T.L., Dulio D. 2011. The Web 2.0 Election: Does the Online Medium Matter? The Journal of Political Marketing, 10: 165-188.

11. Trippi J., Kerbel M.R., Bloom J.D. 2005. Blog for America and Civic Involvement. Harvard International Journal of Press/Politics, 10: 3-27.

12. Trump credits social media for his election. URL: https://www.politico.com/story/2019/10/20/trump-social-media-election-244009.

13. Trump supporters on Twitter during 2016 US election show little evidence of Russian infiltration - new research. URL: https://theconversation.com/trump-supporters-on-twitter-during2016-us-election-show-little-evidence-of-russian-infiltration-new-research-115188.

14. Vargas J.A. 2007. Barack Obama, Social Networking King. The Washington Post, October 6.

(URL) http://voices.washingtonpost.com/44/2007/10/06/barack_obama_social_networking.html (дата обращения: 13.09.2020).

15. Vargas J.A. 2008. Obama Raised Half a Billion Online. The Washington Post, November 20. URL: http://voices.washingtonpost.com/44/2008/11/20/obama_raised_half_a_billion_on.html. (дата обращения: 15.09.2020).

16. Voting Y. 2010. CIRCLE (Center for Information and Research on Civic Learning and Engagement). URL: http://www.civicyouth.org/quick-facts/youth-voting/ (дата обращения: 11.08.2015).

17. Wallsten K. 2010. Yes We Can': How Online Viewership, Blog Discussion, Campaign Statements, and Mainstream Media Coverage Produced a Viral Video Phenomenon. Journal of Information Technology \& Politics, 7: 163-181.

18. Williams Ch.B., Gulati G.J. 2007. Social Networks in Political Campaigns: Facebook and the 2006 Midterm Election, (paper presented at the annual meeting of the American Political Science Association), Chicago, Illinois, 30 August - 2 September.

19. Williams Ch.B., Gula. ti G.J. 2009. Social Networks in Political Campaigns: Facebook and Congressional Elections 2006, 2008. APSA Toronto Meeting Paper 7. 
Via in tempore. История. Политология. 2021. Том 48, № 1 (249-258)

Via in tempore. History and political science. 2021. Volume 48, № 1 (249-258)

ИНФОРМАЦИЯ ОБ АВТОРЕ

Завьялов Артур Андреевич, соискатель на степень кандидата политических наук. ННГУ им. Лобачевского.

\section{INFORMATION ABOUT THE AUTHOR}

Artur A. Zavyalov, applicant for the degree of candidate of political sciences. Lobachevsky State University of Nizhny Novgorod. 